\title{
Kind of Blue and the economy of modal jazz
}

\author{
SAMUEL BARRETT
}

Faculty of Music, University of Cambridge, 11 West Road, Cambridge CB3 9DP

E-mail: sjb59@cam.ac.uk

\begin{abstract}
Kind of Blue has been misrepresented by its promoters. The roots in the blues of the best-selling jazz album have repeatedly been obscured in favour of modal features whose associations are less problematic for those coping with the realities of racial injustice. The case that the blues underpins the modal language of the album is made through reconsideration of the claims made for compositional features of individual tracks. Recognition of the transformed blues language that lies at the heart of the album places questions of its significance on a new footing, opening up the mix of musical languages on the album to interpretation within the context of integrationist ideals of the late 1950s. A critical reading of the album against this backdrop leads to the suggestion that the ongoing commercial success of the album can be partly attributed to a retention of integrationist ideals that masks the reality of persistent inequalities in race relations.
\end{abstract}

On its latest cover, Kind of Blue is pronounced 'perhaps the most influential and best selling jazz album of all time'. The sales figures for the album support at least the second part of this claim: latest estimates provided by Sony Music put total sales at about 4.5-5 million units, with the majority being sold during the last six years - only the record sales of Louis Armstrong are thought to be remotely comparable among recognised jazz artists. ${ }^{1}$ As for 'influence', jazz historians have attributed the seminal status of the album to its exploration of innovative modal techniques as subsequently used in a wide variety of popular music. The relation between the album's musical techniques and its popular reception, however, has never been directly addressed. As a result, most critics have taken the album's own promotional material at face value in attempting to explain its success, i.e. the formal characteristics of the tracks as explained in the liner notes by Bill Evans have been taken as the defining feature of the album:

'So What' is a simple figure based on 16 measures of one scale, 8 of another and 8 more of the first ... 'All Blues' is a 6/8 12-measure blues form that produces its mood through only a few modal changes and Miles Davis' free melodic conception. 'Flamenco Sketches' is a series of five scales, each to be played as long as the soloist wishes until he has completed the series.

For all the interest of Evans' remarks, their status as liner notes needs to be remembered. Not only are his comments sometimes misleading - Evans famously overstates the freedom afforded the players and the spontaneity of the sessions ${ }^{2}-$ but they are not the only statement about the music on the album. The most prominent comment about the album's orientation is made by its title - 'kind of Blue' (s). To take Miles Davis's verbal play as a cue to understanding the music brings not only an altered technical perspective but an altered critical one, for if ever a genre was 
inseparable from social and political circumstance it was (and is) the blues. The title of the album accordingly points away from conventional considerations of the rise of 'modal' jazz to the wider rise to popularity of blues idioms in the 1950s.

The implications of this proposed shift in focus can most readily be appreciated by considering the commonly cited predecessors of Kind of Blue. Four members of the sextet that recorded Kind of Blue in 1959 had the previous year recorded Milestones (Miles Davis, Cannonball Adderley, John Coltrane and Paul Chambers). The difference between the two albums is striking: Milestones is indebted to hard bop, with its fast speeds, angular phrases and driving rhythms; Kind of Blue is more relaxed, spacious, even 'cool'. Despite these stylistic differences, the two albums are closely wedded together in jazz histories: the title track of Milestones is often cited as the earliest fully-fledged example of modal jazz, supposedly based on only two scales. ${ }^{3}$ What is overlooked in this narrative is that both Milestones and Kind of Blue are heavily blues based: four of the six tracks on the former are blues numbers ('Dr. Jackle', 'Sid's Ahead', 'Two Bass Hit' and 'Straight, No Chaser'), two out of five on the latter ('All Blues' and 'Freddie Freeloader'). The extent to which modal jazz is rooted in the blues is underlined by the fact that the title track of Milestones, the often hailed 'first example of modal jazz', is characterised by its blues figuration, with its rising and falling between chordal tones over a static harmony (see Example 1.1). This same figuration was then used as the groove on 'All Blues' on Kind of Blue (see Example 1.2).

If Kind of Blue is heard in the light of blues idioms of the late 1950s more generally, then other striking parallels begin to emerge. In 1958, Art Blakey and the Jazz Messengers recorded the album Moanin', widely regarded as a landmark album in its combination of hard bop with a 'down home' blues style. The title track is marked by a call-and-response theme whose two-bar structure, overall rhythmic profile, and 'Amen' cadence are all echoed in the theme of 'So What' ( see Examples 2.1 and 2.2).

For all the continuity that can be demonstrated between Milestones, hard bop and Kind of Blue, the sense of a fundamental shift in overall feel or attitude remains - a shift from a hard bop sound, with all its African-American resonance, to a softer, cooler sound, characterised in part by Bill Evans' classical tone and impressionist voicings. Put this way, the implications of the stylistic shift with respect to attitudes towards racial integration cannot be ignored. The presence of a white man, Bill Evans, in the most high profile jazz band at the time was offensive to some African-Americans, and accusations that Evans 'didn't play hard enough and fast enough', as epitomised by his playing on Kind of Blue, soon followed. ${ }^{4}$

In seeking a more nuanced account of both the musical techniques and social resonance of Kind of Blue, parallels between blues transformations and social attitudes will be explored here. The various transformations of the blues in the later 1950s have long been interpreted against the backdrop of shifting race relations, with extremes marked out by on the one hand the assimilation of blues idioms in the whitedominated early rock and roll, and on the other the leanings of rhythm and blues and incipient soul music towards a separately defined black identity. ${ }^{5}$ The restrained mixing of styles on Kind of Blue, by contrast, points to the aspirations of the integrationist movement. Although integration had been discussed among liberal elites since the mid-1930s, ${ }^{6}$ movement towards integration only assumed nationwide prominence in the wake of the overturning of 'separate but equal' schooling in 1954 (Brown v. Board of Education of Topeka), and the beginnings of non-violent resistance in the Montgomery bus boycott of 1955 . $^{7}$ The dignified restraint of Kind of Blue points to a use of the blues that is closer in tone to integrationist ideals than any 

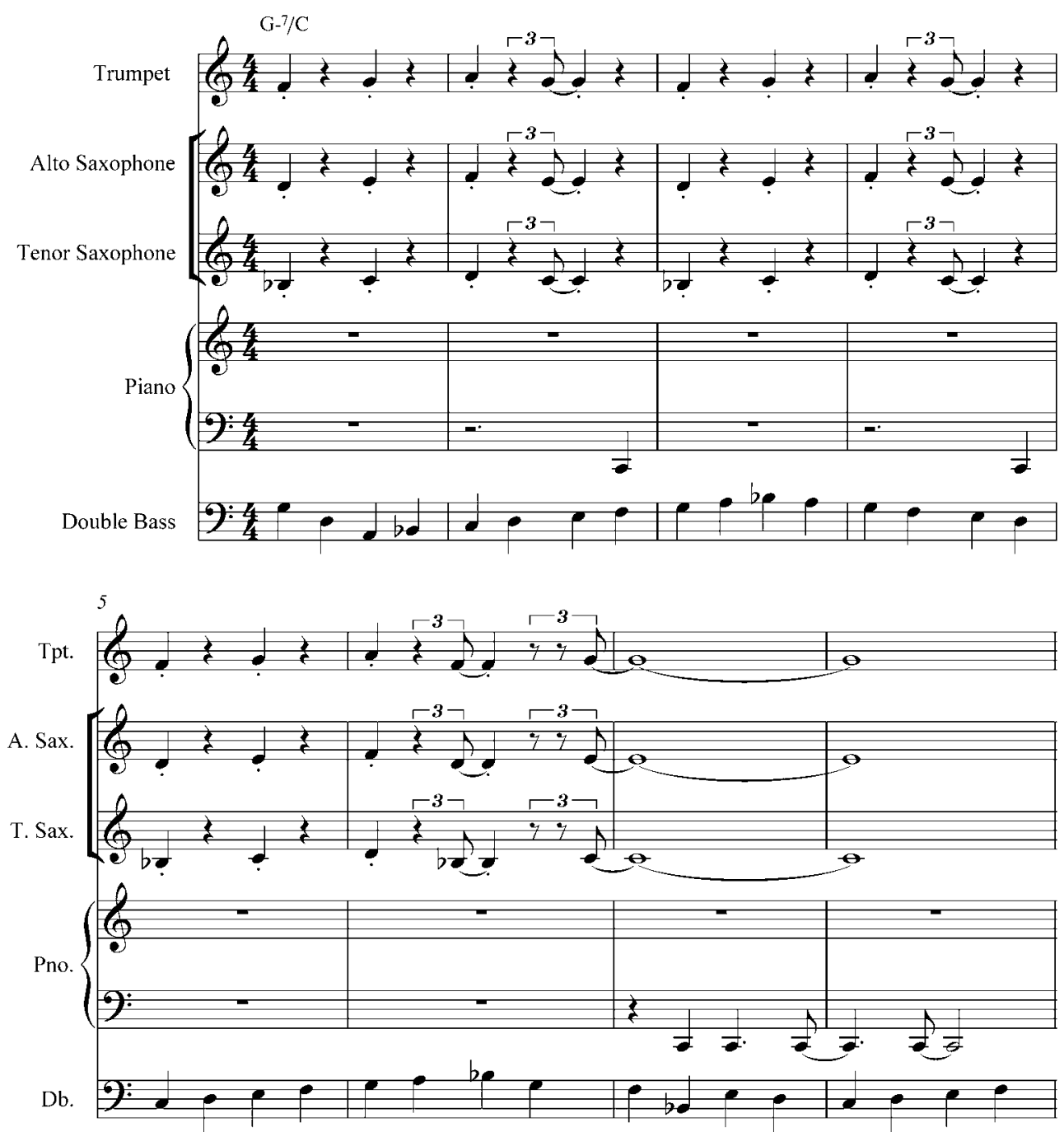

Example 1.1. Opening of Milestones.

separatist tendencies; whether it is open to the same criticisms as the integrationist movement, namely that equality achieved de iure masked ongoing de facto inequalities, remains to be seen.

\section{Modal means}

Two tracks on Kind of Blue are commonly regarded as quintessential examples of modal jazz: 'So What' and 'Flamenco Sketches'. According to most textbook definitions, 'So What' is based on two Dorian scales (on D and Eb) arranged in a standard AABA pattern, and 'Flamenco Sketches' is an extended improvisation based on a series of five scales. The two blues tracks on the album, 'Freddie Freeloader' and 'All Blues', cause more disagreement: according to Mark Gridley 'All Blues' has 'a modal approach to harmony', ${ }^{\prime}$ while for Ekkehard Jost both blues tracks 'bear the 

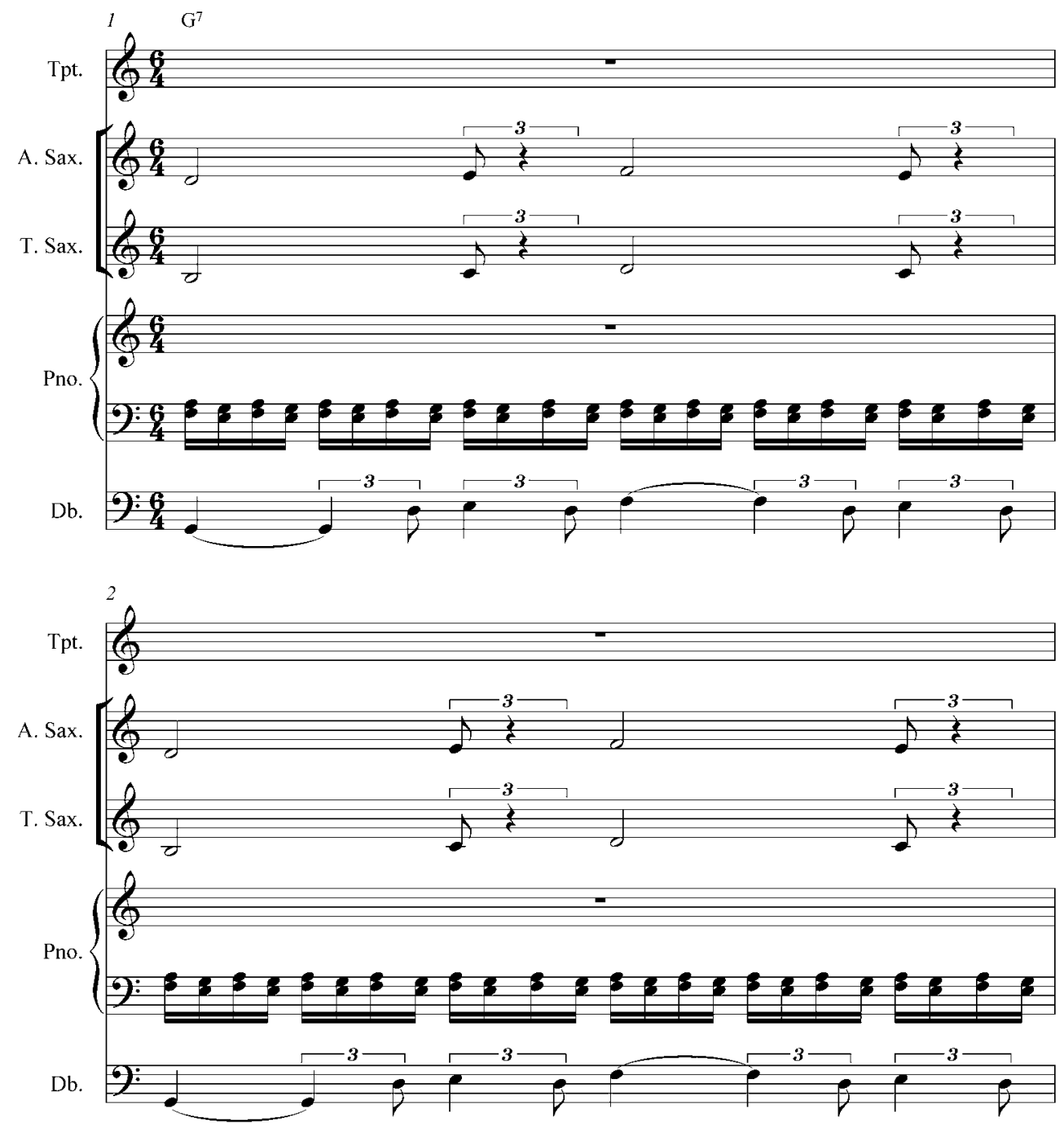

Example 1.2. Opening of All Blues (after 4 bars of vamp).

stamp of modal playing ${ }^{\prime} ;{ }^{9}$ Frank Tirro, on the other hand, ignores both blues tracks in discussing modal jazz, ${ }^{10}$ while James Lincoln Collier claims that all the pieces on Kind of Blue are modal. ${ }^{11}$ The problem hinges on the ambiguity of the term 'modal', which is defined in a number of different ways extending from improvisation based (however loosely) on selected scales, to playing over static harmonic backgrounds, to any harmonic organisation that is not straightforwardly diatonic.

To consider modality in jazz through the lens of the blues provides a partial solution to this problem, for the blues encompasses all the various qualities ascribed to 'modal jazz'. The primarily melodic focus of the blues, which is often limited to a particular scale (such as the pentatonic in much Delta blues), acts as a precedent for the scales provided to the soloists as bases for improvisation in modal jazz. Also, the way a limited number of chords can serve as a loose and not necessarily metrically fixed support for the voice in blues, finds its counterpart in the 'vamps' used in modal 


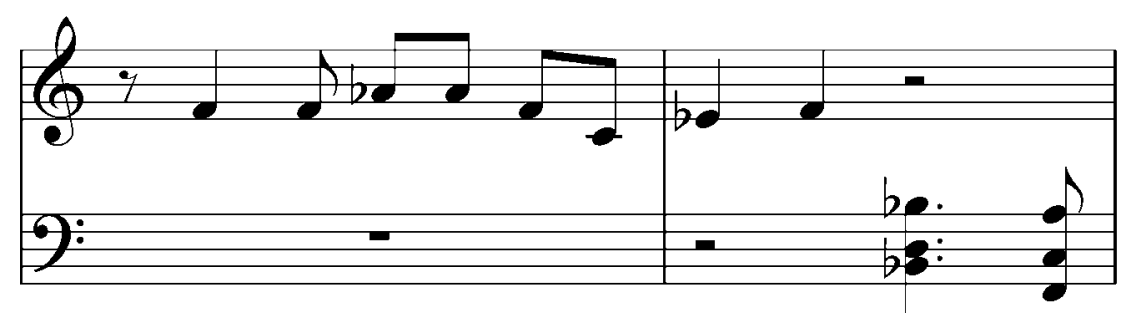

Example 2.1. Moanin', 2-bar theme.

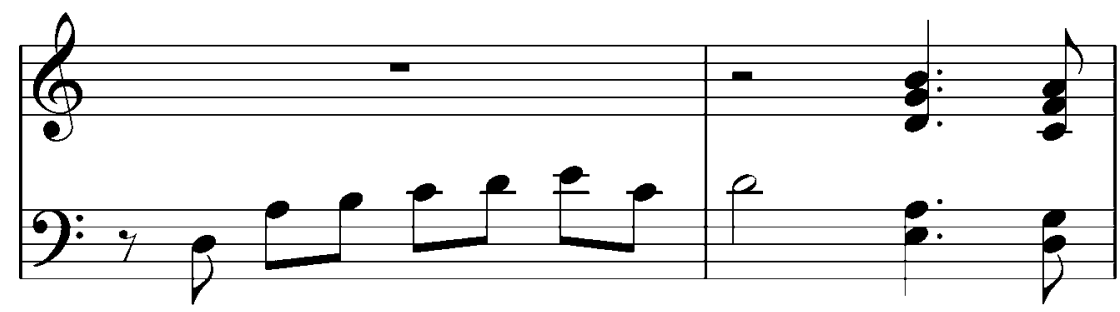

Example 2.2. So What, 2-bar theme.

jazz. The harmonic language of the blues is also not necessarily diatonic, since the tendency to treat the tonic chord as a dominant seventh sets up an ongoing cycle with a weakened sense of any home key. To view Kind of Blue against this background opens up a series of questions about individual tracks, such as why certain scales and not others were chosen on 'So What' and 'Flamenco Sketches', why an ostensibly diatonic track such as 'Blue in Green' sounds just as 'modal' as these tracks, and why the whole album feels like one consistent musical language. In search of answers to these questions, the three tracks that do not explicitly draw on the blues will be considered in detail, beginning with the most controversial.

\section{'Flamenco Sketches'}

Previous attempts to describe the musical design of 'Flamenco Sketches' have examined either scalar or chordal organisation. Among writers who have turned to scales, loosely termed modes, the five scales used on 'Flamenco Sketches' have been the subject of some disagreement. ${ }^{12}$ Ashley Kahn, in his recent study of the making of Kind of Blue brought both clarity and confusion to the matter by enlarging a session photograph showing Cannonball Adderley's chart for 'Flamenco Sketches'. ${ }^{13}$ Alongside the photograph, Kahn listed not the scales on the chart, but the scales that Davis used in his solos since, of the soloists, only Davis plays what might be termed pure 'modal' scales (for a transcription of the scales on Adderley's chart alongside Kahn's list, see Example 3).

There are several discrepancies between Kahn's list of scales and Adderley's chart. A clue to the reason why some of the discrepancies might have arisen lies in Evans' indication at the top of chart, 'Play in [the] sound of these scales', implying that the listed scales served simply as cues to creating overall sonorities. Far from being confronted with an unusual demand to improvise simply on scales, it seems that Adderley was given a set of pitches that could be understood as familiar sonorities. At the second segment, Adderley was given Eb Dorian, which could easily be 


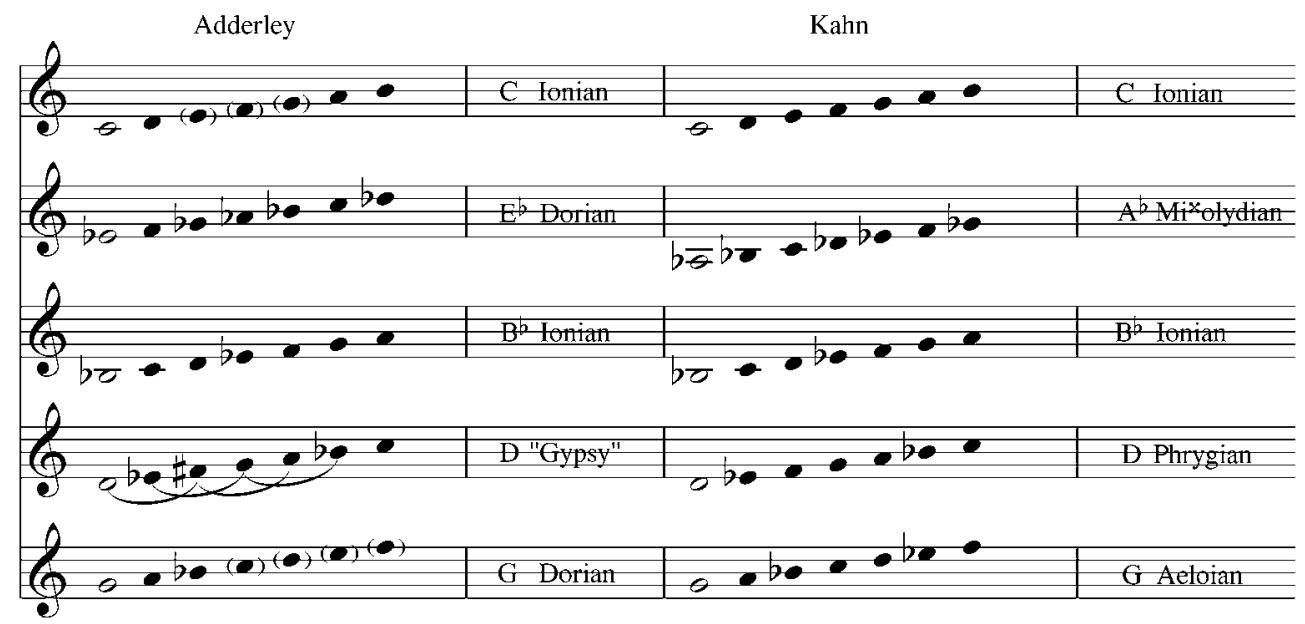

Example 3. Modal scales in 'Flamenco Sketches'. The notes in brackets are conjectural since they cannot be seen clearly on the picture of the chart provided by Kahn. An apparent error in Kahn's list occurs at the fifth segment, where Davis plays prominent E naturals rather than E flats, i.e. he selects pitches from a $G$ Dorian rather than $G$ Aeolian set. The reconstruction of this fifth scale on Adderley's chart follows conventional practice in representing Davis's scale selection. At the fourth segment, Kahn gives the conventional D Phrygian, since Davis plays notes exclusively from a D Phrygian scale, but underneath his solo Evans plays alternating $D$ major and $E$ flat chords as well as introducing $C$ naturals. The scale that encompasses Evans' note selection is therefore precisely the one that Adderley had in front of him: $D, E b, F \#, G, A, B b, C$. At the second segment, Kahn gives the usual $A b$ Mixolydian, but Adderley had Eb Dorian in front of him. Here it would seem that the commonly cited scale is a better representation of what was played than the chart, for although there is no difference in pitch content between Eb Dorian and Ab Mixolydian, the fact that Paul Chambers repeatedly plays 5-1 onto Ab suggests that the scale is more accurately described as Ab Mixolydian.

understood as Eb minor, and at the fourth segment the slurs added to Adderley's chart indicate that two major triads a minor second apart (as played by Evans) were at the front of his mind. ${ }^{14}$ What Adderley read from the chart was therefore two major scales $(\mathrm{C}$ and $\mathrm{B} b$ ), two minor scales ( $\mathrm{E} b$ and $\mathrm{G}$ ) and one exotic scale to which slurs were added to clarify an internal structure of two major triads.

Any suggestion that the five scales of 'Flamenco Sketches' were treated as familiar major and minor sonorities lends weight to Barry Kernfeld's suggestion that this track is built not on modal scales, but a series of chordal vamps. ${ }^{15}$ Evans' two-chord oscillations over V-I roots in the first three segments can easily be understood as a vamp structure, ${ }^{16}$ and a case can even be made for an overall tonal organisation to the track (see Example 4). There are, however, difficulties in describing the sonorities explored in 'Flamenco Sketches' in such functional terms. Most notably, the track ends not on $\mathrm{C}$ major but on $\mathrm{G}$ minor, and each soloist cadences in the $\mathrm{G}$ minor section rather than continuing to $\mathrm{Cmaj} 7$ as both the end and the beginning of the cycle. Even if the sequence were regarded as starting on chord IV of G minor, this would not explain why the final Gmin9 serves as a closing point and Cmaj7 sounds as a new beginning each time around the sequence.

A simpler way to hear 'Flamenco Sketches' is as an elaboration of a single and static blues sonority. Key to this consideration is the fact that all the roots of the harmonies on 'Flamenco Sketches' are drawn from a single C Aeolian scale, i.e. C, D, $\mathrm{Eb}, \mathrm{F}, \mathrm{G}, \mathrm{Ab}$, B b. That the harmonies of 'Flamenco Sketches' can be associated through 


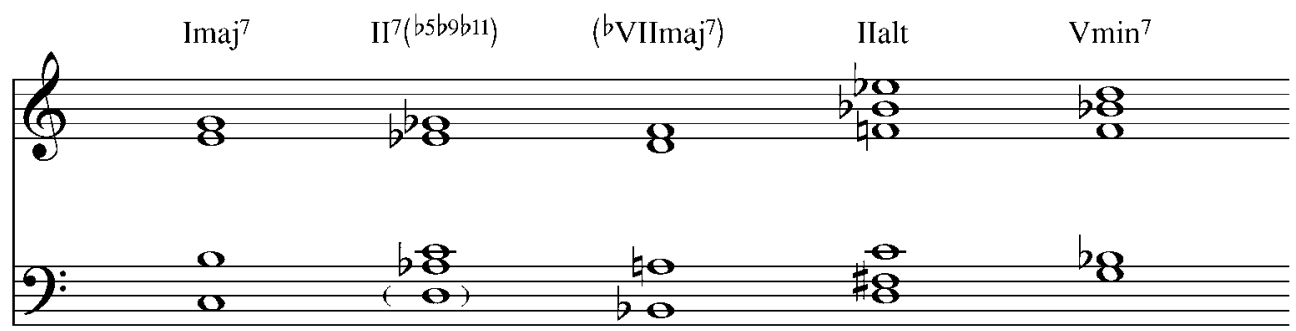

Example 4. Kernfeld's proposed harmonic progression for 'Flamenco Sketches'. The fourth ('Flamenco') segment can be heard as an altered dominant seventh chord since the juxtaposition of $F$ sharps in the backing with front line $F$ naturals transforms the overall sonority into a dominant seventh on $D$ with an added flattened ninth (Eb), sharpened ninth ( $F$ natural), and a flattened thirteenth $(B b)$. It follows that the final two scales in the cycle can be considered a cadential II-Vmin in preparation for I at the beginning of the new cycle, which acts as both a point of arrival and departure. As for the earlier chords in the sequence, Kernfeld argues that the bVI at the second segment operates as a tritone substitution for II (even though D natural is not used in the second segment scale), which is then only interrupted by bVII before returning to II. Kernfeld therefore argues that the whole progression works as an interrupted and heavily inflected II-Vmin-I.

a C Aeolian scale is not as arbitrary as it might first appear, for the practice became a common procedure in rock music. ${ }^{17}$ The principle is that of building harmonies on a scale over which the blues can be played, and it is this exploration of local colours within an overall blues sonority that binds together 'Flamenco Sketches'. Moreover, it is not just that the roots of the harmonies are drawn from a scale with flattened third, sixth and seventh, but that the entire sound world is derived from the principle explored in much blues of introducing flattened alterations or 'blue notes' against a diatonic major scale. On 'Flamenco Sketches', starting from an initial white note chord-scale of $\mathrm{C}$ major, all subsequent chord-scales lie on the flat side, i.e. they flatten select tones from the home sonority. This flat-side orientation includes the ambiguity of the Flamenco scale, which can be expressed as having either three flats (Eb, Gb and $\mathrm{B} b)$ or 2 flats and a sharp $(\mathrm{E} b, \mathrm{~F} \#$ and $\mathrm{B} b)$, mirroring the ambiguous status of the flattened fifth or raised fourth in blues practice. Considering 'Flamenco Sketches' as an exploration of local colours within an overall blues sonority based on $C$ also serves to explain why the initial Cmaj7 sounds as a home chord without the same pull that it would have in a tonal scheme: the chord on the fifth degree serves equally well as a final cadence point given the absence of a leading note in the global C Aeolian scale.

\section{'Blue in Green'}

'Blue in Green' shares several similarities with 'Flamenco Sketches': the tonic scale of 'Blue in Green' is again a white note scale (in this case, D Dorian), and the roots of the harmonies are taken from D Aeolian (D, E, F, G, A, B b, C, D). As on 'Flamenco Sketches', a dominant minor is used and the sense of a tonal centre is equally diffuse. There is also a similar stratification of texture, with Chambers keeping to roots, Evans exploring shifting chordal textures in the mid-range, and the front-line players staying close to single scales.

Part of the reason for the similar musical language on 'Blue in Green' lies in Evans' voicings, which are not only rich in fourths (as in the sus chords played by Evans on 'Flamenco Sketches'), but also make harmonic implications ambiguous. A striking illustration of this practice is the opening chord on 'Blue in Green': as often 


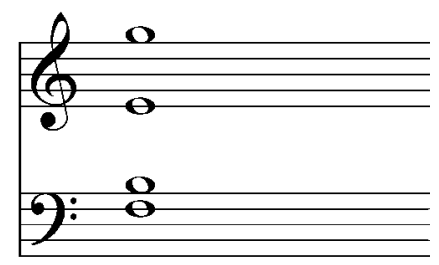

( $\mathbf{O})$

Example 5. Evans' ambiguous voicing.

happens later in the track, Imin7 is realised as a stack of fourths, topped by a third over the D sounded by the double bass ( see Example 5). Rather than a simple Imin7, what Evans plays could therefore again be described as a sus chord, which can be heard as either Dmin13, or Emin9/D or G13/D. Such ambiguity leads to difficulties in describing Evans' voicings in functional terms; if they are treated as extensions to a diatonic frame, then the overall harmonic structure would read as in Example 6 (Evans' voicings).

Although a possible description, the complexity of this sequence is at odds with the simplicity of the D minor scales used by Davis and Coltrane in their improvisations. A way of simplifying the description, as well as providing a clue as to how Evans' voicings relate to the front-line soloists is to translate these chords into scales on their roots (see Example 6 - scale pitches and scale names). This sequence is not only simpler to grasp, but suggests the harmonies in 'Blue in Green' serve as scalar sonorities rather than as triadic harmony. ${ }^{18}$ The arrangement of these scales follows a familiar pattern: dominant scales (whether in the form of altered scales or the Mixolydian) precede main points of rest that outline a simple frame of I-bVI-I-V-I (see Example 7).

This pattern reflects a simple blues scheme, with a substitution of $b$ VI instead of IV that is easily understood since they are equivalent scales, and Evans himself exchanges bVI and IV as the opening chord of the overall cycle (after both of Davis's solos). As in 'Flamenco Sketches', an open-endedness is then brought to the cycle by treating I as both the ending point of the cycle and the beginning of a new one.

Even though a sequence loosely related to the blues can be traced in abstract, the chords following the dominant sevenths are not easily heard as centres. This is in part due to the irregular metrical distribution, in which these chords occur respectively on the third, fifth, seventh and ninth bars of the cycle. The opening two bars of the cycle, however, correspond to the two chords given to Evans by Miles, and may be considered an external appendix to an otherwise conventional eight-bar structure of I-IV/bVI-I-V. Heard in this way, 'Blue in Green' is a mixture of bluesinspired modality and a richly chromatic diatonic ballad: at the local level, the points of rest follow a sequence with a loose association to blues practice, and at the global level individual chord-scales are built on degrees of the Aeolian scale. It is this overall blues quality that not only links the track to 'Flamenco Sketches', but also serves to explain why the simplified scalar language used by Coltrane and Davis works so effectively.

\section{'So What'}

'So What' is also characterised by Evans' voicings. The famous 'So What' chords can once again be described as sus chords; in particular, Emin7sus and Dmin7sus (see 

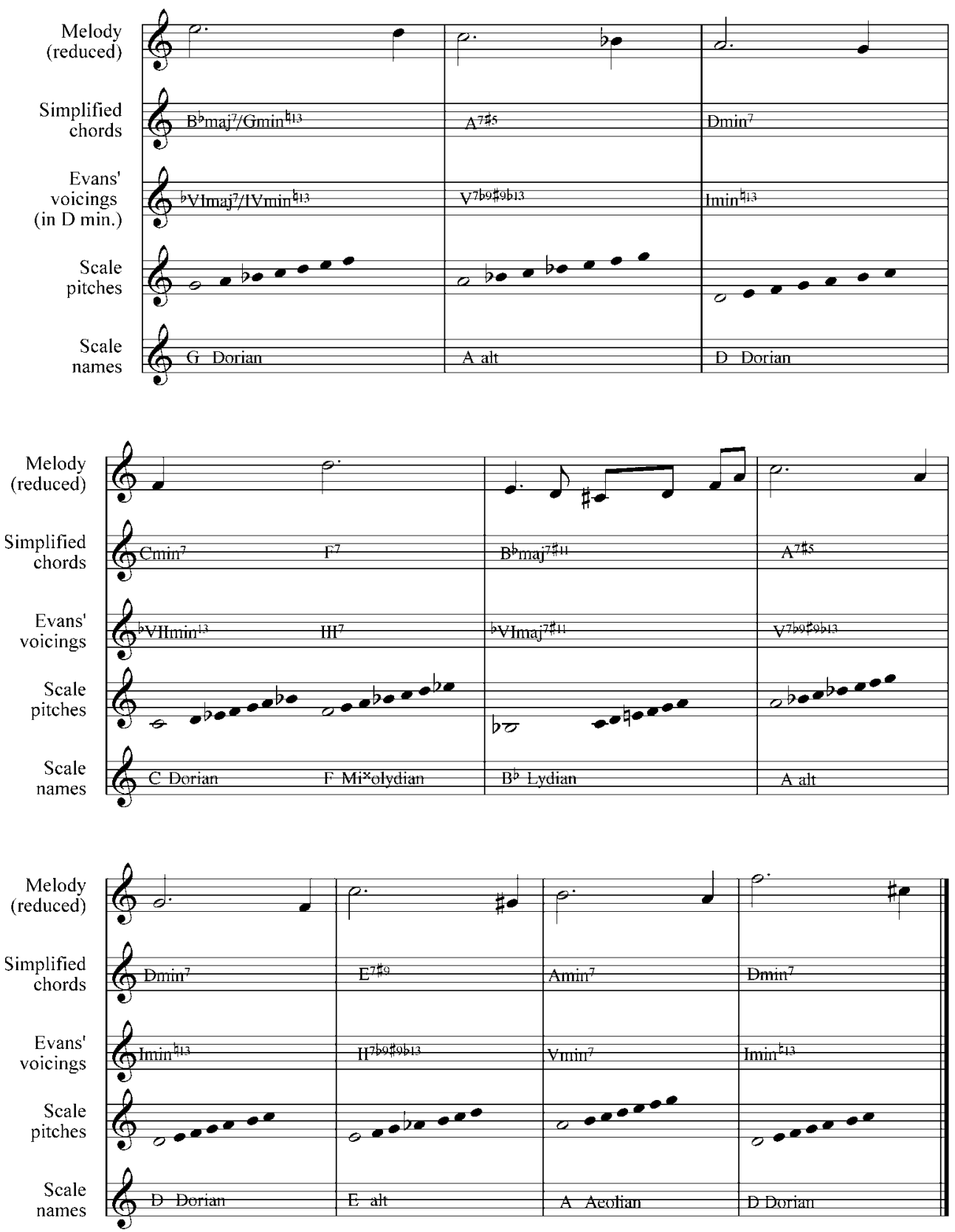

Example 6. Reductions of 'Blue in Green'.

Example 8). That they are rarely described as such seems to be due to the fact that they are worked into a call-and-response structure with the bass and that they are so readily heard as a musical translation of 'So What'. Yet the bass line serves not only as a melody, but also to define the modal sonority, establishing D as the tonal centre of a D Dorian scale by outlining its dominant (A minor) before coming to rest on the D (see Example 9). The first chord of the 'So What' riff extends this sonority, described as 


$\begin{array}{ll}\text { G Dorian - Aalt. — D Dorian } & \text { IV-V7-I } \\ \text { C Dorian - F mixolydian - Bb Lydian } & \text { VII-III7-bVI } \\ \text { A alt. - D Dorian } & \text { V7-I } \\ \text { E alt.- A Aeolian } & \text { II7- }-\underline{V} \\ \text { D Dorian } & \underline{I}\end{array}$

Example 7. Modal structure in 'Blue in Green'.

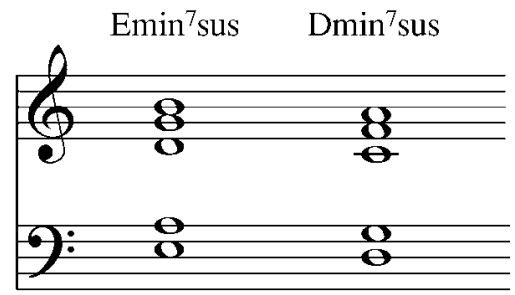

Example 8. 'So What' chords.

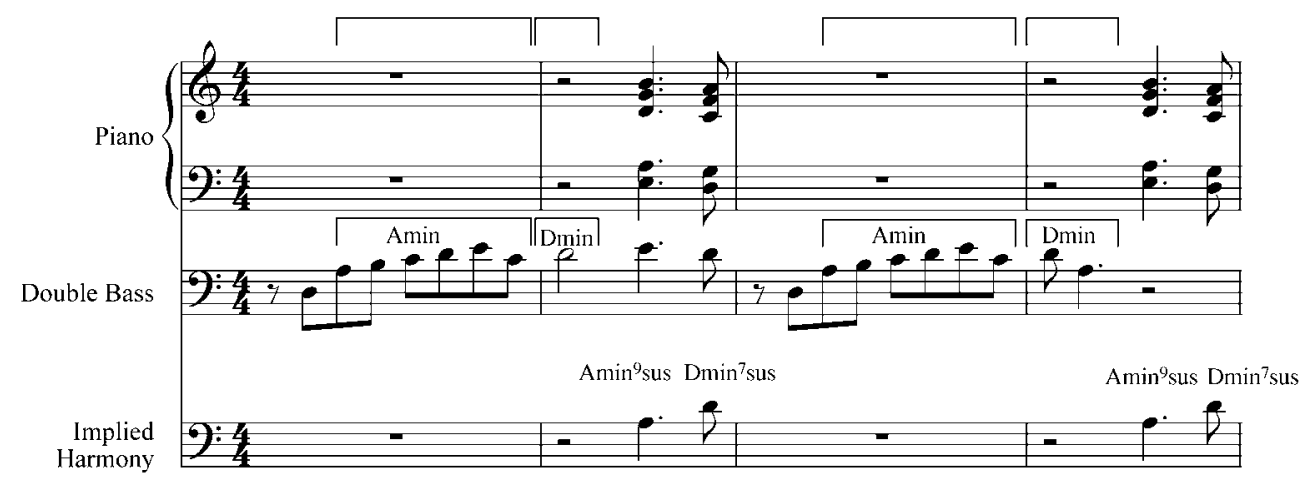

Example 9. Implied 'So What' harmony.

Emin7sus above, but which might also be described as Amin9sus against the A minor just outlined by the bass. While 'So What' heard horizontally is thus a set of sliding fourths topped by thirds (or Emin7sus and Dmin7sus), heard vertically the chordal implication is Amin9sus followed by Dmin7sus. This vertical implication is reinforced on the second appearance of the bass line, which this time returns to an A that can be heard to continue underneath the first chord.

The same principle of movement within a static field achieved through sus chords thus holds for 'So What' as for 'Flamenco Sketches' and 'Blue in Green'. Yet the question of how the two chord-scales on 'So What' relate remains - it could be that the two Dorian scales should be heard simply as adjacent vamps or, following Kernfeld, the bII relation may be an outgrowth of the 'chromatic upper neighbour motion' explored in the fourth segment of 'Flamenco Sketches'. ${ }^{19}$ A more substantial link to 'Flamenco Sketches' lies in the fact that the two scales reproduce the same pitch sets as the opening two levels on that track; that is, movement from a scale of no flats to one of five flats. ${ }^{20}$ Within this movement two pitches remain stable ( $\mathrm{C}$ and $\mathrm{F}$ ), the reason for which seems to be that these are the only pitches that cannot be flattened from a white note scale without reproducing notes already in the home scale $(\mathrm{Cb}=\mathrm{B}, \mathrm{F} b=\mathrm{E})$. The scale of 5 flats $(\mathrm{B} b, \mathrm{E} b, \mathrm{~A} b, \mathrm{D} b$ and $\mathrm{G} b)$ might therefore be described as a white 
note scale with the most possible flats introduced ( $b 7, b 3, b 13$, b9 and b5). Understood in this way, the two chord-scales sound as an extended oscillation within an overall single static field rather than two separate sonorities whose relation needs to be explained in structural terms. What is heard most clearly on this track, but has already been heard on both 'Flamenco Sketches' and 'Blue in Green', is a horizontal transformation of a soundworld commonly heard vertically in the blues - the introduction of flattened or 'blue' notes against major scale harmony not as vertical, but horizontal inflections.

\section{Modal significance}

The significance of the fragmentation and re-orientation of a blues language on Kind of Blue extends well beyond the note-bound analysis conducted so far. In the suggestive words of Amiri Baraka, what Davis was seeking to do on this album was to express the blues 'not just as form, but as feeling and colour'. ${ }^{21}$ This aesthetic shift shares broad similarities with abstract expressionism in its collapsing of hierarchies between foreground and background and in its focus on its own materials of production: as heard on Kind of Blue, harmony and melody are folded within modal sonorities, and scales serve not as abstractions from practice but as primary creative tools. Baraka has also pointed to the social overtones of integration in Kind of Blue within the context of the mix of identities that he sees as characterising Davis's musical output. As Baraka says about Davis's interracial bands, 'There is something in the mix that Miles wants to hear. It might be commercial, to some extent, but it is also social and aesthetic' ${ }^{22}$ In pointing to 'social and aesthetic' implications, Baraka directs our attention beyond the fascination with details of the making of Kind of Blue, explored in much previous discussion of the album, to the broader political and artistic movements within which it was situated. In order to listen in to that 'something in the mix', careful attention needs to be paid to the significance of the musical language of Kind of Blue within both the culture of the late 1950s and that of more recent years.

That modal jazz might symbolise freedom is a familiar trope. ${ }^{23}$ The reduction in the number of chords is often said to allow players a freer rein in melodic invention, releasing them from outlining fast-moving changes with standard formulae, allowing the possibility of both continuing for as long as desired and creating melodic lines from any combination of scale degrees. In contrast to this ideal, the practice on Kind of Blue might seem a peculiarly restrictive version of freedom. Despite Evans' claim in the liner notes that the scales on 'Flamenco Sketches' are 'to be played as long as the soloist wishes', each soloist chooses standard patterns of four or eight bars. Similarly, the front-line soloists do not explore a fundamentally new style of melodic improvisation, but keep close to styles that had been explored over the previous decade: Davis plays 'within the changes' creating space through his use of rests and held notes, Coltrane explores scalar runs and organises his phrasing around goal tones and short repeated ideas, while Adderley retains his fluid funky style with its strong rhythmic emphasis and even implies chord progressions within modal areas. ${ }^{24}$ The role of the rhythm section is similarly far from free: Chambers and Evans are restricted by the need to keep close to vamp figurations and Jimmy Cobb offers little in the way of rhythmic interjections or variations.

It would seem then that questions of musical freedom demand closer attention. On the basis of the analysis presented here, a different interpretation of the transformation effected by modal jazz may be suggested. The parallel to be made with the 
other arts and society is not so much with release from former structures as with a shift in organisation from the vertical to the horizontal, or what Jameson termed a new cultural 'spatialisation' and 'depthlessness' ${ }^{25}$ As applied to Kind of Blue, what can be heard on the album is less an integration of musical styles than a bricolage of elements drawn from various musical styles: Evans' voicings derived from classical modernism, Davis's allusions to the thumb piano and Gospel traditions, Spanish folk music, the similarities to Indian raga and even Evans' comparisons in the liner notes to Japanese art. ${ }^{26}$ Where there is stylistic transformation is in the language of the blues, which is aligned with other musical languages by being re-worked into scalar structures. What musical integration there is on Kind of Blue is therefore achieved only in the abstract, i.e. modal scales are shared by the multiple stylistic idioms used without these stylistic idioms themselves becoming in any way unified. Rather than serving as a symbol of concrete integrations, the musical language of the album would seem to provide an image of co-existence whose only shared point of reference is the blues.

Heard in this way, it is worth considering how far the spectacular commercial success of the album, especially in the last decade, masks an ongoing failure of social integration to achieve its stated aims. As George Lipsitz has recently observed, despite the legislative advances of the civil rights movement, discriminatory segregation continued in practice through urban renewal programs, which created EuropeanAmerican suburbs with vastly higher rates of government investment than the inner cities inhabited by minority racial groups. These discriminatory policies in housing lead in turn to marked inequalities in employment and education, continuing what Lipsitz calls a 'possessive investment in whiteness' that has characterised ongoing discrimination in favour of European-Americans. ${ }^{27}$ The reception of Kind of Blue has arguably echoed the same tension between social idealism and material reality. On the one hand, the musical language of Kind of Blue provides a utopian vision specific to the late 1950s and early 1960s; a moment of hope in the possibility of integration of traditions of high and low, classical and vernacular, black and white. On the other hand, the album ideally meets the demands of a rapidly expanding market with its need to appeal to the widest possible audience using the minimum of means. The danger that this dual operation represents is that the ultimate failure of the integrationist movement, as witnessed by the rise of black nationalism from the mid-1960s onwards and the persistence of economic inequalities up to the present day, is concealed by the opportunity afforded the individual consumer to buy into the dream-like image of integration afforded by the co-existence of European-American and African-American musicians and musical traditions.

Such a dual economy would accord with the position of the blues in the thinking of the most prominent writer on African-American culture today. For Houston Baker, the blues is not simply a genre, but 'a matrix' that is 'an enabling script in which African-American cultural discourse is inscribed' ${ }^{28}$ Furthermore, according to Baker, cultural pluralism failed and continues to fail precisely over the blues, its vernacular, folk and mass status separating it from the educated, wealthy and literate selfdefinition of America. The blues remain to the dominant culture what earlier integrationists such as Richard Wright termed a 'form of things unknown', ${ }^{29}$ an 'unknowable' status that is as much epistemological as social. As Baker says, 'The metaphysical privileging of AMERICA by Integrationist Poetics renders the vernacular, in the governing terms of the poetics themselves, an aporia - a self-engendered paradox ${ }^{\prime 30}$ In other words, the promotion of a utopian vision of integration in forms 
of high rhetoric simultaneously served to obscure and place out of mind everyday reality and its characteristic modes of expression, including most notably the blues.

Kind Of Blue is clearly not what Baker would term the blues, yet in so far as the album aligns blues idioms with European-American musical languages, it reflects the ideals of integrationist poetics and is open to the same criticisms. Most notably, although the blues is a shared point of reference, it is not a common language: straight blues playing was off-limits to Evans, the one European-American musician on the album ( the piano chair was taken by Wynton Kelly for 'Freddie Freeloader' ). In so far as social relations are played out on the album, Kind of Blue stands not so much for integration as a shift in the status of the blues: the blues in its most straightforward form remains a preserve of African-Americans, but a soft-hued modal blues is presented as a music for all America. Yet the more the blues language is transformed so that it can align multiple musical styles, the more it recedes from view to be sensed without being explicitly recognised. The dangers inherent in this approach are readily apparent: the blues becomes, as in rock and roll, a property to be enjoyed by European-Americans, whilst simultaneously concealing African-American identity from view.

In attributing Kind of Blue's popular success to a broad-based EuropeanAmerican enthusiasm for the blues from the mid-late 1950s onward, a simultaneous African-American interest in and reception of the blues cannot be overlooked. The perception of the blues as an essentially African-American genre was one shared, and in its own way appropriated, by many northern, urban, educated African-Americans: as expressed most forcibly by Baraka, the blues were symptomatic of the 'Negro experience' in America. ${ }^{31}$ Yet this vision is as romantic as that entertained by many European-Americans in its portrayal of a primitive rural tradition of the blues, untainted by commerce and direct in its expression of personal feelings that spoke for all conditions of African-Americans. ${ }^{32}$ What is overlooked in this romanticisation of the blues is a recognition of its status as a mass-recorded entertainment form that, although practised mainly by African-Americans, had long been enjoyed and practised by European-Americans. ${ }^{33}$ Kind of Blue arguably stands squarely within this pluralistic and openly commercial tradition, drawing on a multiplicity of styles and in so doing maintaining a syncretic tradition at the very moment that others were attempting to restrict it to musical or racial essentials. Although the popular success of the album is due to the way in which it transforms the blues from musical outsider to invisible insider, there remains hope that in recognising the blues content of the album its ongoing popularity may be both embraced as a sign of its artistic success and further reflected upon for what it tells of a failure to remove the need for such an other-worldly image of harmonious integration. ${ }^{34}$

\section{Copyright acknowledgements}

Permission has been obtained from Capitol Jazz and Classics and from Sony Music for the publication of transcriptions from all three albums listed in the text.

\section{Endnotes}

1. These estimated sales figures were provided by Sony UK in a private correspondence dated 12 December 2002.
2. On the freedom of the soloists in 'Flamenco Sketches', see below. Evans' claim that 'Miles conceived these settings only hours before the 
recording dates' and that 'without exception the first complete performance of each was one "take" " has been shown to be erroneous by Kahn, who also draws attention to Evans' exaggeration about the care needed with parchment in Japanese visual art: see Kahn (2000, pp. 96, 154).

3. The two scales usually cited for the title track of Milestones are G Dorian for the A section and A Aeolian for the B section. For Mark Gridley, 'All Blues' was 'a continuation of the modal interest Davis had shown on the title track of Milestones' (Gridley 1978, p. 182). For Bob Belden, the title track of Milestones was 'the first recording of Davis's new direction' (Belden 2000, p. 395).

4. 'Many blacks felt that since I had the top small group in jazz and was paying the most money that I should have a black piano player [...] Then a lot of people were saying he [Bill Evans] didn't play fast enough and hard enough for them, that he was too delicate' (Davis 1989, p. 221).

5. On the translation of blues idioms into rock and roll, see Middleton (1972, pp. 148-61), Hatch and Millward (1987, pp. 68-86) and Headlam (2002, pp. 158-66). The relation of rhythm and blues and soul music to the development of black consciousness is explored at length in Ward (1998).

6. Gunnar Myrdal's An American Dilemma, a sociological study funded by the Carnegie Corporation in 1935 that was first published in 1944, presented arguments for integration (see Rose 1964). The book was immediately criticised by Ralph Ellison for its equation of American culture with white culture (Ellison 1973).

7. For a full account of the development of the non-violent and integrationist ideology of the civil rights movement by Martin Luther King during the 1950s, see Branch (1988, pp. 69-271).

8. Gridley (1978, p. 182).

9. Jost $(1975$, p. 21$)$.

10. Tirro (1993, p. 361).

11. Collier (1978, pp. 432-3).

12. Jost gives $G$ Aeolian as the scale for the last segment, and A flat Ionian as the scale for the second (Jost 1975, p. 22). G Aeolian and A flat Mixolydian are given for the same segments in Kerschbaumer (1978, p. 92).

13. Kahn (2000, p. 70).

14. Since the overall aim of the fourth segment was to produce a Flamenco-like sonority, Adderley's scale does not contradict Miles Davis's superimposed Phrygian. The Phrygian is itself a typical scale type in Flamenco, and adding Davis's Phrygian colouration to the extra C sharps and E naturals added by John Coltrane and Adderley results in a bi-modal scale also commonly used in Flamenco, i.e. D, $\mathrm{Eb}, \mathrm{E}, \mathrm{F}, \mathrm{F} \#, \mathrm{G}, \mathrm{A}, \mathrm{B} b, \mathrm{C}, \mathrm{C} \#$. On scales used in Flamenco, see Katz (2004).

15. Kernfeld (1981, pp. 137-44).

16. Evans plays alternating chords underneath the soloists on the first four segments: Cmajor7/
Gsus at the first, $\mathrm{A} b 7 /$ Ebsus at the second, Bbmajor7/Fsus at the third and Dmajor/ Ebmajor at the fourth.

17. Eric Clapton's recordings of 'Layla', 'Old Love', 'Bad Love', 'Miss You' and 'Cocaine', for example, all feature Aeolian sequences using chords built on bVII and bVI. Most notably, the chorus of 'Layla' switches between Im, bVI and bVII ( $\mathrm{D}$ minor, $\mathrm{Bb}$ major and $\mathrm{C}$ major). For further examples of Aeolian structures in rock music, see Middleton (1990, pp. 198-200). Middleton also cites an unpublished paper: A. Björnberg, 'On Aeolian harmony in contemporary popular music', paper presented to the Third International Conference of IASPM, Montreal.

18. D Dorian functions as I, F Mixolydian as bIII, G Dorian as IV, A Aeolian as V, B b Lydian as bVI, and C Dorian as bVII

19. Kernfeld (1981, p. 157).

20. This shift is anticipated in Evans' recording of Leonard Bernstein's 'Some Other Time' (Riverside, 15 December 1958). As often noted, the chords used in the first segment of 'Flamenco Sketches' (Cmaj7-G7sus) derive from the opening of the Bernstein tune. What has remained unnoticed is that the chords of the second segment in 'Flamenco Sketches' are also found in the same tune. Bernstein's tune switches at the middle eight to bVI, which is treated, as in 'Flamenco Sketches', in alternation with a suspended fourth chord on its own dominant, i.e. bVI-bIIIsus (or Abmaj7-Eb7sus). When Evans improvised on 'Some Other Time', he extended the opening two chords over the whole of the first sixteen bars before switching to bVI7-bIII7sus, anticipating exactly the opening sequence of chords used in 'Flamenco Sketches'.

21. Baraka (1987, p. 303).

22. Baraka (1987, p. 294). On the mix of identities in Davis's work, see also Tomlinson (1992, pp. 79-93).

23. See, most recently, Monson (1998, pp. 149-68).

24. Adderley frequently implies IImin-V-I progressions over the bar line (e.g. bars 1-2,3-4 and 5-6 at the opening of his solo).

25. A new cultural 'spatialisation', which can be traced back to the late 1950s and early 1960s, is central to Jameson's reading of postmodernism: see Jameson (1991, pp. 1-54).

26. On Evans' derivation of voicings from early twentieth-century Spanish composers and French Impressionists, see Mehegan (1965, pp. 16-17). For the sources of Davis's modal inspirations, see Davis (1989, pp. 224-5).

27. Lipsitz (1998).

28. Baker (1984, p. 3).

29. Baker's reference is to Wright (1964, pp. 69-105).

30. Baker (1984, p. 69).

31. Baraka 1963, passim but especially ch. 6 ('Primitive Blues and Primitive Jazz').

32. The criticism that Baraka locates the authenticity and authority of the blues in simplistic 
categories of class and colour is most fully explored in the review of Blues People by Ralph Ellison (Ellison 1967, pp. 247-58). On parallel constructions of the blues by EuropeanAmericans in the country blues revival, see Titon (1993, pp. 220-40).

33. 'White' contributions to the blues have been stressed by several writers: see especially Bane (1982) and Cook (1973). For the suggestion that, although rooted in traditions of the rural black south, the blues was fundamentally shaped by 'white-black' interaction in an urban context and mediated by recordings, see, with further references, Keil (1991, pp. 232-4).

34. My sincere thanks are extended to Jim Barrett, Roger Parker and the two anonymous readers of this journal for invaluable advice in the preparation and revision of this article.

\section{References}

Baker (Jr.), H.A. 1984. Blues, Ideology, and Afro-American Literature: A Vernacular Theory (Chicago \& London, University of Chicago Press)

Bane, M. 1982. White Boy Singin' the Blues (Harmondsworth, Penguin)

Baraka, A. 1963. Blues People: The Negro Experience in White America and the Music that Developed from It (New York, William Morrow)

Baraka, A. 1987. 'Miles: "One of the Great Mother Fuckers"' ', in The Music: Reflections on Jazz and Blues, ed. A. and A. Baraka (New York, William Morrow), pp. 286-316

Belden, B. 2000. 'Miles Davis', in The New Oxford Companion to Jazz, ed. B. Kirchner (New York \& Oxford, Oxford University Press)

Branch, T. 1988. Parting the Waters: Martin Luther King and the Civil Rights Movement 1954-63 (London, Macmillan)

Collier, J.L. 1978. The Making of Jazz: A Comprehensive History (London, Hart-Davis MacGibbon)

Cook, B. 1973. Listen to the Blues (New York, C. Scribner's Sons)

Davis, M., (with Troupe, Q.) 1989. Miles: The Autobiography (London, Macmillan)

Ellison, R. 1967. 'Blues people', in Shadow and Act (London, Secker \& Warburg), pp. 247-58

1973. 'An American dilemma: a review', in The Death of White Sociology, ed. J.A. Ladner (New York, Vintage Books), pp. 81-5

Gridley, M.C. 1978. Jazz Styles (Englewood Cliffs, NJ, and London, Prentice-Hall)

Hatch, D., and Millward, S. 1987. From Blues to Rock: An Analytical History of Pop Music (Manchester, Manchester University Press)

Headlam, D. 2002. 'Appropriations of blues and gospel in popular music', in Cambridge Companion to Blues and Gospel Music, ed. A. Moore (Cambridge, Cambridge University Press)

Jameson, F. 1991. 'The cultural logic of late capitalism', in Postmodernism, Or, the Cultural Logic of Late Capitalism (London, Verso), pp. 1-54

Jost, E. 1975. Free Jazz (Graz, Universal Edition)

Kahn, A. 2000. Kind of Blue: The Making of the Miles Davis Masterpiece (New York, Da Capo Press)

Katz, I.J. 2004. 'Flamenco', Grove Music Online, ed. L. Macy (accessed 13/08/04), http:// www.grovemusic.com $\rangle$

Keil, C. 1991. Urban Blues (Chicago \& London, University of Chicago Press)

Kernfeld, B.D. 1981. Adderley, Coltrane, and Davis at the Twilight of Bebop: The Search for Melodic Coherence (1958-9), Ph.D. Dissertation, Cornell (Ann Arbor)

Kerschbaumer, F. 1978. Miles Davis: Stilkritische Untersuchungen zur musikalischen Entwicklung seines Peronsalstils (Graz, Akademische Druck und Verlagsanstalt)

Lipsitz, G. 1998. 'The possessive investment in whiteness', in The Possessive Investment in Whiteness: How White People Profit from Identity Politics (Philadelphia, Temple University Press), pp. 1-23

Mehegan, J.F. 1965. Contemporary Piano Styles: Jazz Improvisation IV (New York \& London, Watson-Guptill Publications, Amsco)

Middleton, R. 1972. Pop Music and the Blues: A Study of the Relationship and its Significance (London, Gallancz) 1990. Studying Popular Music (Milton Keynes \& Philadelphia, Open University Press)

Monson, I. 1998. "“Oh Freedom": George Russell, John Coltrane, and modal jazz', in In the Course of Performance: Studies in the World of Musical Improvisation, ed. B. Nettl with M. Russell (Chicago \& London, University of Chicago Press), pp. 149-68

Rose, A.M. 1964. The Negro in America: The Condensed Version of an American Dilemma (New York, Harper \& Row)

Tirro, F. 1993. Jazz: A History (New York \& London, Norton)

Titon, J. 1993. 'Every day I make the blues: reflections on the 1960s blues revival', in Transforming Tradition: Folk Music Revivals Examined, ed. N.V. Rosenberg (Urbana, University of Illinois Press), pp. 220-40

Tomlinson, G. 1992. 'Cultural dialogics and jazz: a white historian signifies', in Disciplining Music: Musicology and its Canons, ed. K. Bergeron and P.V. Bohlman (Chicago \& London, University of Chicago Press), pp. 79-93 
Ward, B. 1998. Just My Soul Responding: Rhythm and Blues, Black Consciousness and Race Relations (London, University College London Press)

Wright, R.N. 1964. 'The literature of the negro in the United States', in White Man, Listen! (Garden City, Doubleday \& Co. ), pp. 69-105

\section{Discography}

Art Blakey, Moanin'. Blue Note BN 4003

Miles Davis, Milestones. Columbia CL 1193

Miles Davis, Kind of Blue. Columbia CL 1355

\section{CAMBRIDGE JDURNALS}

